\title{
Comparison of Various Configuration of Wireless Power Transfer System
}

\author{
Martin Zavřel ${ }^{1)}$ and Vladimír Kindl ${ }^{2)}$ \\ 1) 2) University of West Bohemia, Department of Electromechanics and Power electronics, Plzeň, Czech Republic, \\ e-mail: ${ }^{1)}$ zavrelm@kev.zcu.cz, ${ }^{2)}$ vkindl@kev.zcu.cz.
}

\begin{abstract}
This article deals with mutual comparison of different resonant tank configurations of the wireless power transfer (WPT) systems. Tested compensation configurations are classified as series-series, series-parallel, parallel-series and parallel-parallel and all of them are operated with the input and output frequency converters and other supplementary electronics. As parameter we chose the transfer distance and load. The comparison is made according to changes in overall system efficiency and power delivered to the load along varying both the load and operational distance. All theoretical findings are experimentally verified and discussed in the conclusion section.
\end{abstract}

Keywords - wireless power transfer system, efficiency, power, resonant tank compensation.

\section{INTRODUCTION}

In the recent last years, the electro-mobility is getting more and more in the forefront, not just like a technical interest, but primarily like potential replacement for vehicles using combustion engines [1]. Electric vehicles (EVs) charging is a crucial technical problem that includes more than one technical discipline. The classical conception of the charging stations (cable chargers) introduces several disadvantages like potential electric shock hazard [2], necessary manual manipulation with plugs and possible plugs incompatibility. Solution of these problems may be found in the wireless charging stations using resonant inductive power transfer [3]. This type of charging stations requires no direct physical manipulation with plugs which therefore increases the charging safety [4].

Since these systems are quite complex having several possible configurations, they may act differently when changing operational conditions or even may provide with contradictory properties.

The WPT systems can be divided into several groups systems using inductive coupling elements with at least two coils, systems using inductive-resonant coupling elements and systems using capacitive coupling elements.

This article focusses mainly on operational properties of the WPT system using the inductive-resonant coupling connected in four different configurations; series-series, series-parallel, parallel-series and parallel-parallel [5-9]

The system evaluation is based on results from numerical simulation [13-14] and from experimental measurement [10-12] of $5 \mathrm{~kW}$ WPT system prototype. As some comparative parameters we introduce the power transferred to the load and the system operational efficiency including the input inverter, resonant tank and output rectifier. This term is usually called the dc-dc efficiency.

\section{WPT SYSTEM DESCRIPTION}

\section{A. Compensation Strategy}

The article analyses WPT systems using compensation capacitors on both sides, the primary and the secondary side. In this case, the resonant tank may be connected in four different configurations; series-series (S-S), seriesparallel (S-P), parallel-series (P-S) and parallel-parallel (P-P) configurations. Equivalent electrical circuit of these configurations are shown in Fig. 1.

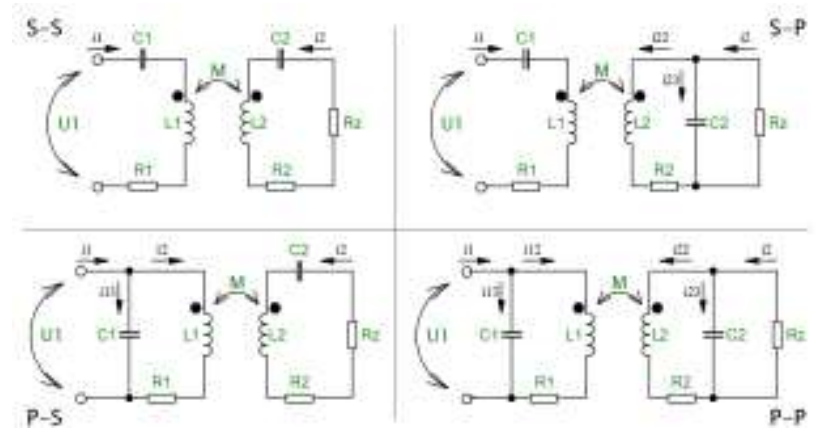

Fig. 1. WPT system configurations.

The parameters $C_{1}$ and $C_{2}$ represent the primary and the secondary compensation (resonant) capacitors. The coupling coils form the self-inductances of values $L_{1}$ and $L_{2}$ and exhibit the series parasitic resistances $R_{1}$ and $R_{2}$. The mutual magnetic coupling is represented with mutual inductance $M$. Finally, the parameter $R_{z}$ stands for the load. Since the circuit electrically resonates on the main frequency (1)

$$
f_{01}=\frac{1}{2 \pi \sqrt{L_{1} C_{1}}}, \quad f_{02}=\frac{1}{2 \pi \sqrt{L_{2} C_{2}}}
$$

it also can reach the resonant state at "side-band" frequency (2).

$$
f_{01 x}=\frac{1}{2 \pi \sqrt{\left(L_{1} \pm M\right) C_{1}}}, \quad f_{02 x}=\frac{1}{2 \pi \sqrt{\left(L_{2} \pm M\right) C_{2}}}
$$

According to the SAE standards [13], the resonant frequency must be designed to the frequency band $85 \mathrm{kHz}$

\section{B. WPT System Description}

As seen in Fig. 2, the WPT system consists of five functional components: DC voltage source, input inverter, output rectifier and the load or the load converter. 
The power supply includes programmable DC source which allows to regulate properly the primary DC voltage.

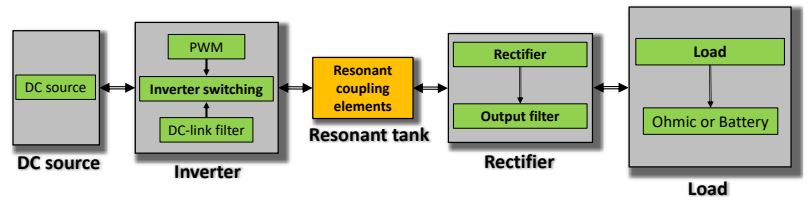

Fig. 2. WPT system chain.

The input inverter is designed as a single-phase fullwave inverter based on SiC J-FET semiconducting modules working with the switching frequency $f_{s}$. The output rectifier is also constructed from the $\mathrm{SiC}$ modules, but it is designed as a passive full-bridge rectifier equipped with an output filter.

Power loss converted into heat in both frequency converters are for the inverter calculated as (3) and for the rectifier as (4).

$$
\begin{gathered}
\Delta P_{D C A C}=2\left[R_{\text {on }} I_{1 r m s}^{2}+U_{o n} I_{1 r m s}+\left(E_{\text {oN }}+E_{\text {off }}\right) f_{S}\right] \\
\Delta P_{A C D C}=2\left[R_{\text {on }} I_{R Z \text { avg }}^{2}+U_{\text {on }} I_{R z \text { avg }}\right]
\end{gathered}
$$

Here $R_{o n}$ represents the J-FET or diode on-state resistance, $U_{\text {on }}$ is the J-FET or diode on-state voltage, $I_{1 \text { rms }}$ is the rootmean-square value of the output inverter current, $I_{R Z}$ avg is the average value of the output rectifier current and $\mathrm{E}_{\mathrm{on}} / \mathrm{E}_{\text {off }}$ represents the J-FET turn-on and turn-off switching energy.

The load is designed as pure resistive, whose value is driven by the programmable electronic load.

The experimental laboratory set-up is shown in Fig. 3. The functional blocks organization presented in Fig. 2 fully correspond to the assembly seen in Fig. 3 .

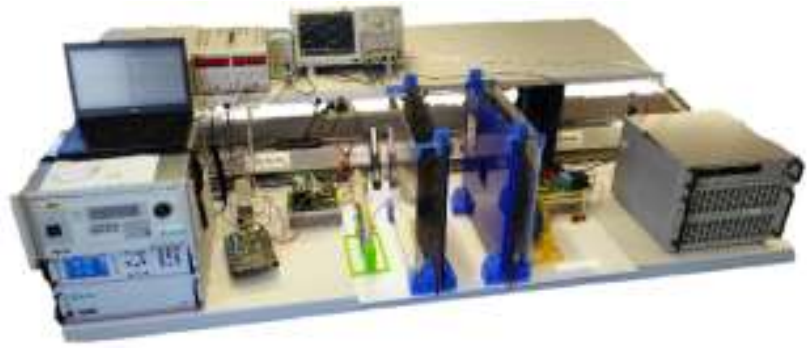

Fig. 3. WPT prototype set-up.

\section{DESIGN OF COUPLING ELEMENTS}

In order to reach the same voltage on the primary and secondary side, the coupling elements are identical. Therefore, the series parasitic resistance and selfinductance on both coupling coils might be considered to be the same. The compensation capacitor $C_{2}$ is set so, it fully compensates the inductance $L_{2}$. Then the compensation capacitor $C_{1}$ must be set according to the net impedance $\bar{Z}_{c}$ seen by the input voltage source. The goal is to meet the power factor equal to unit, or in other words the imaginary part of $\bar{z}_{c}$ equal to zero. For example, the net impedance (fundamental wave) for the seriesseries configuration is given by (5).

$\bar{Z}_{c S-S}=$

$\frac{j-C_{2} R_{z} \omega-j\left(C_{1} L_{1}+C_{2} L_{2}\right) \omega^{2}+C_{1} C_{2} L_{1} R_{z} \omega^{3}+j C_{1} C_{2}\left(L_{1} L_{2}-M^{2}\right) \omega^{4}}{C_{1} \omega\left[C_{2} \omega\left(L_{2} \omega-j R_{z}\right)-1\right]}$
The load $R_{z}$ is connected to the resonant tank via the rectifier, so hence it must be recalculated accordingly (6).

$$
R_{Z A C}=R_{Z}=\frac{8}{\pi^{2}} R_{Z D C}
$$

Equation (6) does take into account neither the nonlinearities of the semiconducting devices nor their other parasitic properties.

Assuming modified (1), we may $C_{2}$ calculate as (7):

$$
C_{2}=\frac{1}{4 \pi^{2} f_{0}^{2} L_{2}}
$$

where $f_{0}$ is the selected resonant frequency.

The capacitor $C_{1}$ is found from condition (8).

$$
\mathfrak{I}\left\{\bar{Z}_{c}\right\}=0
$$

After necessary manipulation we can find values for $C_{1}$ in (9)-(12).

$$
\begin{gathered}
C_{1, S-S}=\frac{C_{2} L_{2}}{L_{1}} \\
C_{1, S-P}=\frac{C_{2} L_{2}^{2}}{L_{1} L_{2}-M^{2}} \\
C_{1, P-S}=\frac{C_{2} L_{2}}{L_{1}+\frac{M^{4}}{L_{1} L_{2} C_{2} R_{Z}^{2}}} \\
C_{1, P-P}=\frac{C_{2} L_{2}^{2}\left(L_{1} L_{2}-M^{2}\right)}{\left(L_{1} L_{2}-M^{2}\right)^{2}+\frac{C_{2} M^{4} R_{Z}^{2}}{L_{2}}}
\end{gathered}
$$

As it is obvious from (9)-(12), the primary compensation capacitor varies with changing $R_{z}$ or $M$ for each compensation topology except the series-series connection.

\section{SYSTEM MODEL DESCRIPTION}

Electrical circuits presented in Fig. 1 may be described according to Kirchhoff's laws as:

For the S-S configuration we write (13)-(14).

$$
\begin{array}{r}
u_{1}=\frac{1}{C_{1}} \int_{0}^{t} i_{1}(t) d t+u_{C 1(0)}+R_{1} i_{1}+L_{1} \frac{d i_{1}}{d t}+M \frac{d i_{2}}{d t} \\
0=\frac{1}{C_{2}} \int_{0}^{t} i_{2}(t) d t+u_{C 2(0)}+R_{2} i_{2}+L_{2} \frac{d i_{2}}{d t}+M \frac{d i_{1}}{d t}+R_{z} i_{2}
\end{array}
$$

For the S-P configuration we write (15)-(17)

$$
\begin{gathered}
u_{1}=\frac{1}{C_{1}} \int_{0}^{t} i_{1}(t) d t+u_{C 1(0)}+R_{1} i_{1}+L_{1} \frac{d i_{1}}{d t}+M \frac{d i_{22}}{d t} \\
L_{2} \frac{d i_{22}}{d t}+M \frac{d i_{1}}{d t}+R_{2} i_{22}=\frac{1}{C_{2}} \int_{0}^{t} i_{21(t)} d t+u_{C 2(0)} \\
0=\frac{1}{C_{2}} \int_{0}^{t} i_{23}(t) d t+u_{C 2(0)}+R_{z} i_{2}
\end{gathered}
$$

For the P-S configuration we write (18)-(20).

$$
\begin{gathered}
u_{1}=\frac{1}{C_{1}} \int_{0}^{t} i_{13}(t) d t+u_{C 1(0)} \\
L_{1} \frac{d i_{12}}{d t}+M \frac{d i_{2}}{d t}+R_{1} i_{12}+=\frac{1}{C_{1}} \int_{0}^{t} i_{13}(t) d t+u_{C 1(0)} \\
0=\frac{1}{C_{2}} \int_{0}^{t} i_{2}(t) d t+u_{C 2(0)}+R_{2} i_{2}+L_{2} \frac{d i_{2}}{d t}+M \frac{d i_{12}}{d t}+R_{z} i_{2}
\end{gathered}
$$

And for the P-P configuration we write (21)-(24).

$$
\begin{gathered}
u_{1}=\frac{1}{C_{1}} \int_{0}^{t} i_{13}(t) d t+u_{C 1(0)} \\
L_{1} \frac{d i_{12}}{d t}+M \frac{d i_{22}}{d t}+R_{1} i_{12}+=\frac{1}{C_{1}} \int_{0}^{t} i_{13}(t) d t+u_{C 1(0)} \\
L_{2} \frac{d i_{22}}{d t}+M \frac{d i_{12}}{d t}+R_{2} i_{22}=\frac{1}{C_{2}} \int_{0}^{t} i_{21(t)} d t+u_{C 2(0)} \\
0=\frac{1}{C_{2}} \int_{0}^{t} i_{23}(t) d t+u_{C 2(0)}+R_{z} i_{2}
\end{gathered}
$$


Since the system operated at the resonant frequency exhibits strong frequency selectivity, we may simplify the model using application the symbolic-complex method.

For example, for the S-S configuration (13)-(14) changes into the form (25).

$$
\left[\begin{array}{c}
\bar{U}_{1} \\
0
\end{array}\right]=\left[\begin{array}{cc}
R_{1}+j\left(\omega L_{1}-\frac{1}{\omega C_{1}}\right) & -j \omega M \\
-j \omega M & R_{2}+R_{z}+j\left(\omega L_{2}-\frac{1}{\omega C_{2}}\right)
\end{array}\right]\left[\begin{array}{l}
\bar{I}_{1} \\
\bar{I}_{2}
\end{array}\right]
$$

Where $\bar{I}_{1}$ represents the primary-loop current oriented clockwise, $\bar{I}_{2}$ is the secondary-loop current oriented counter-clockwise and $\bar{U}_{1}$ is the fundamental wave magnitude of the supplying voltage.

The system efficiency (28) is then given as a ratio of the output (27) and input (26) powers with consideration of the losses (3)-(4). This brings better overlapping of the simulated and measured results.

$$
\begin{gathered}
P_{1}=\frac{1}{2}\left|\bar{U}_{1} \bar{I}_{1}^{*}\right| \\
P_{2}=\frac{1}{2} \frac{8}{\pi^{2}} R_{Z}\left|\bar{I}_{2}\right|^{2} \\
\eta=\frac{P_{2}-\triangle P_{A C D C}}{P_{1}+\triangle P_{D C A C}}
\end{gathered}
$$

\section{Simulation AND MEASUREMENT RESUlts}

The described model and system prototype were used for investigation of different operating conditions influence on the WPT system.

\section{A. Influence of Various Coupling Coefficient and Various Load on the Compensating Capacitor}

The analysis focuses mainly on influence of the changing coupling coefficient $k$ (or mutual inductance) and varying load resistance (see Figs. 4 and 5).

From both figures it is evident, that the $S-S$ configuration is generally resistant to $k$ and $R_{Z}$ changes, and therefore $C_{1}$ can be simply set according to Thomson's law.

Further, while the S-P configuration is almost resistent similarly to the $\mathrm{S}-\mathrm{S}$ compensation, both remaining configurations (P-S and P-P) are quite sensitive on any chage in $k$ and $R_{z}$. Hence, we claim that the S-S and S-P compensating configurations are both more applicable to the E-vehicles charging, than the P-P and P-S configurations.
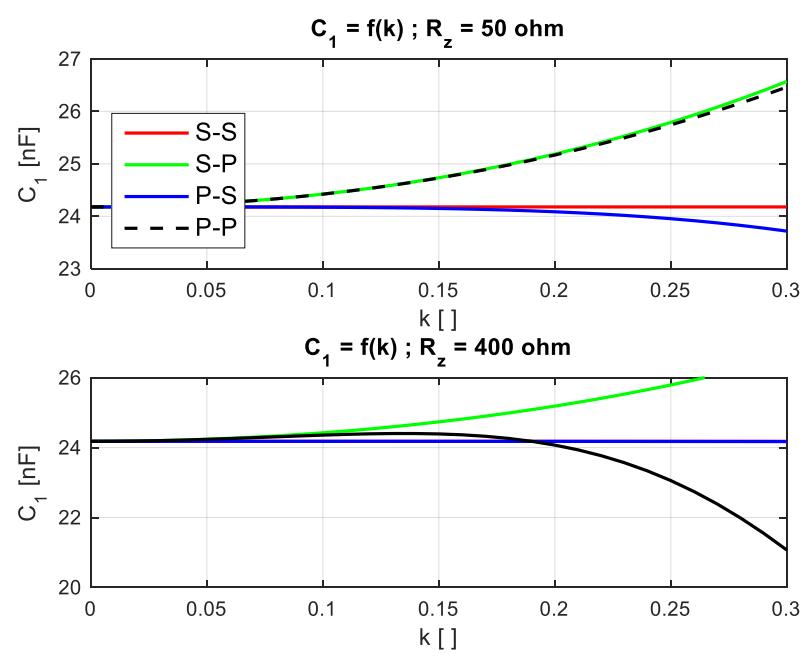

Fig. 4. Influence of $k(M)$ on the primary compensating capacitor.
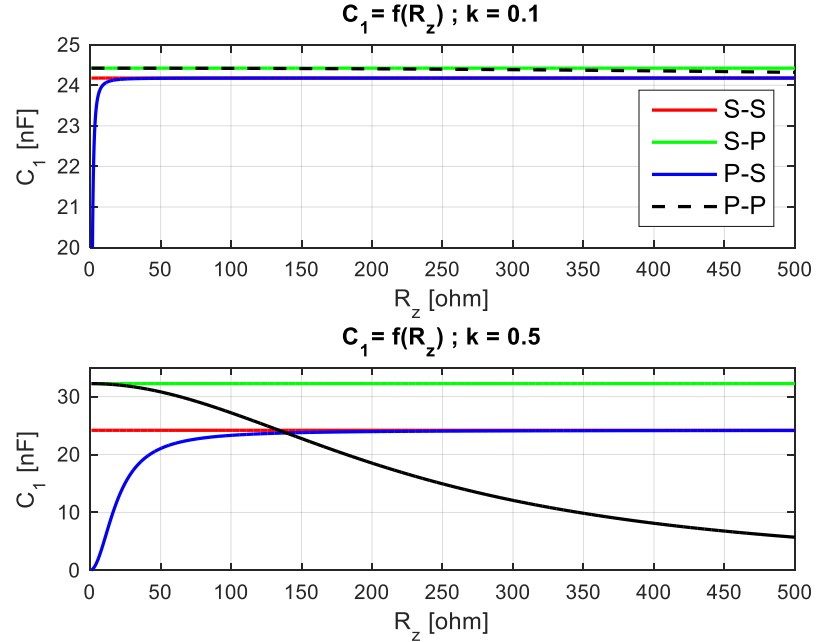

Fig. 5. Influence of the changing load and coupling coefficient on the primary compensating capacitor value.

\section{B. Influence of Various Coupling Coefficient and Various Load on Power and Efficiency}

Next figures show results measured on the system having constant compensating capacitor $C_{1}$ set by Thomson's law. Measured parameters are the maximum load power (Fig. 6), the maximum load power when reaching the highest possible efficiency (Fig. 7) and overall (DC to DC) efficiency (Fig. 8) of the WPT system when changing load and transfer distance.

The results confirm that the P-P and P-S configurations are not fully usable for the E-vehicles charging since the power delivered to the load and efficiency are quite low. Moreover, the S-S configuration provides us with better performance than the S-P, since the transferred power (for the same voltage) when the used S-P configuration is only up to $677 \mathrm{~W}$, but if the S-S configuration is used, the transfer power is much higher, up to $5138 \mathrm{~W}$.

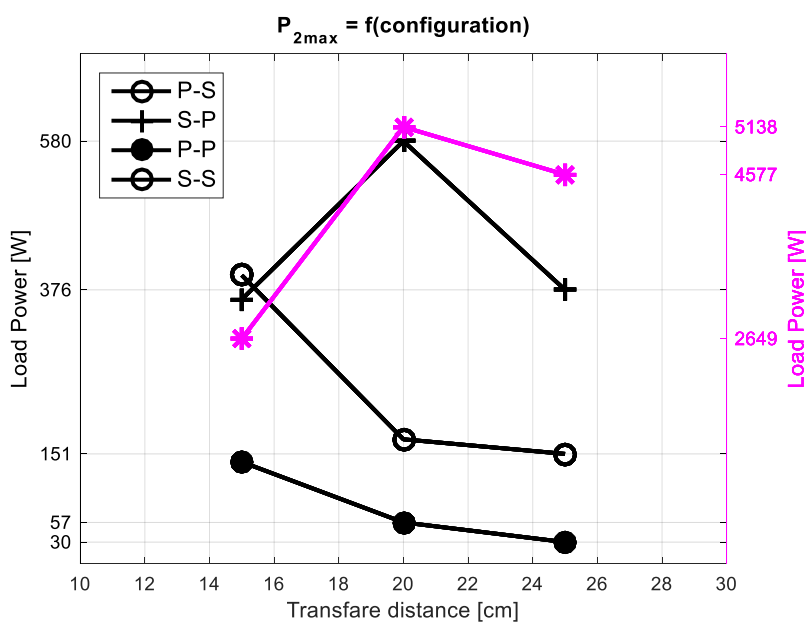

Fig. 6. Measured maximum transferred power. 


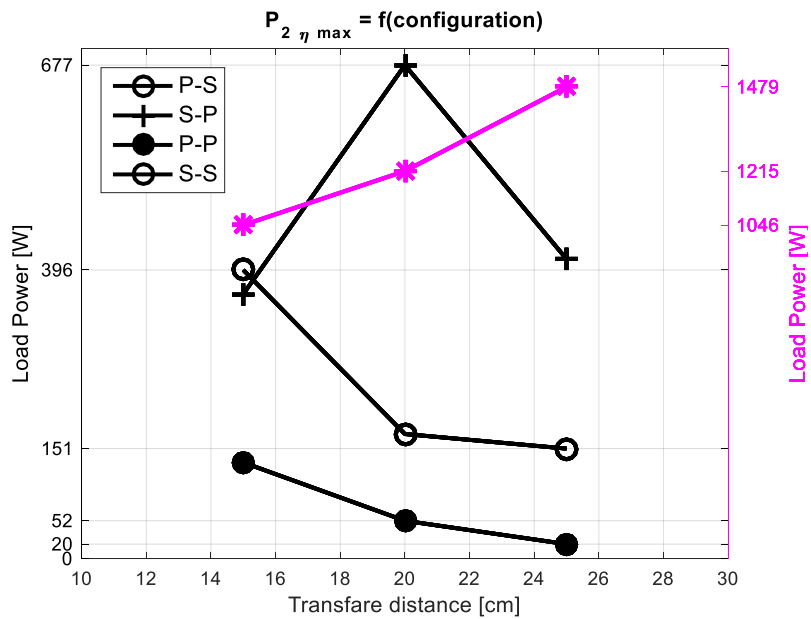

Fig. 7. Maximum transferred power when reaching the highest efficiency.

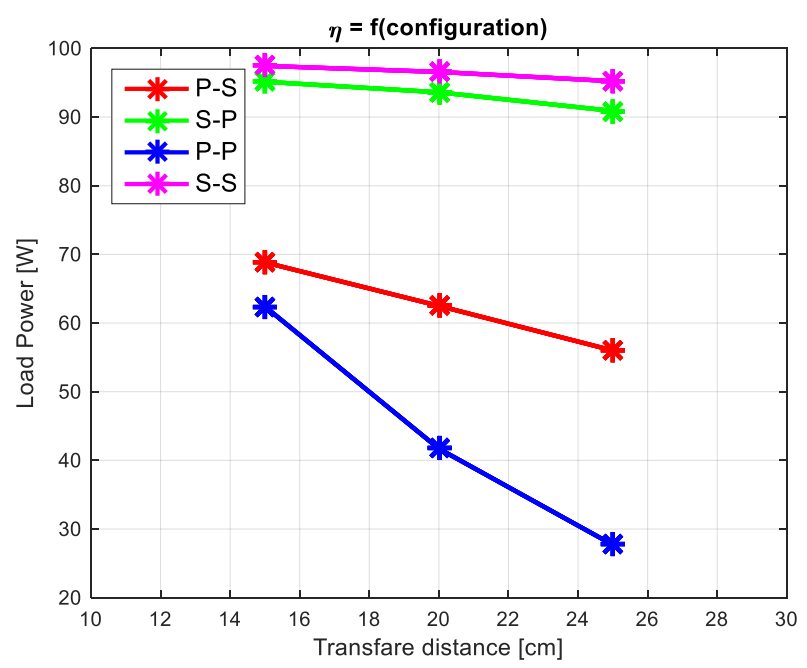

Fig. 8. Measured DC to DC system efficiency.

\section{Influence of Switching Frequency on Power and Efficiency}

System sensitivity to the switching frequency $f_{s}$ is next parameter which allows us to evaluate usability of the configuration for real applications. Following figures (Figs. 9 and 10) show the efficiency maps (top), input DC power maps (bottom right) and DC load power maps (bottom left).

Figure 9 shows the data maps for the S-S configuration. As it is evident the efficiency map is relatively flat which could be beneficial when charging under real parking conditions. The system is not so sensitive to the mutual misalignment of the coupling coils.

Figure 10 displays the data maps for the S-P configuration that exhibit stronger frequency selectivity and overall lower efficiency.

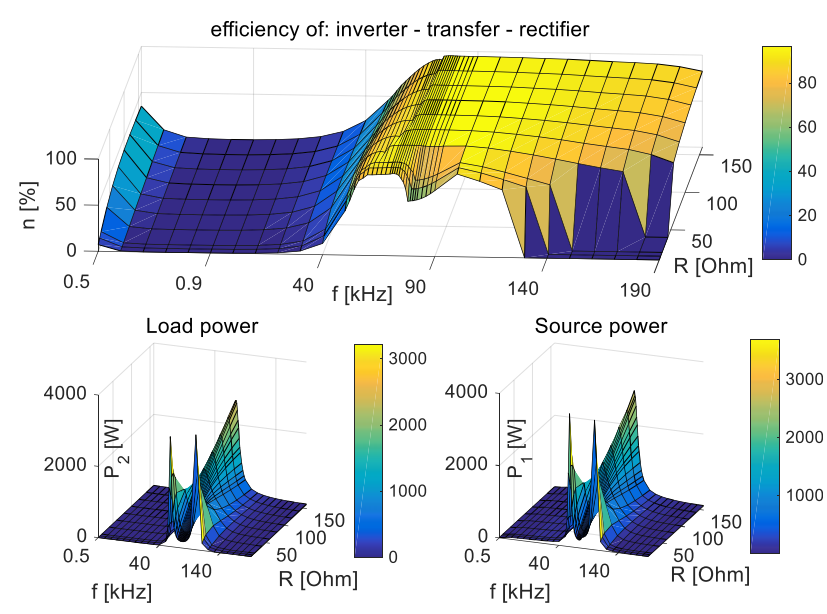

Fig. 9. Measured load power and efficiency maps of the S-S configuration.

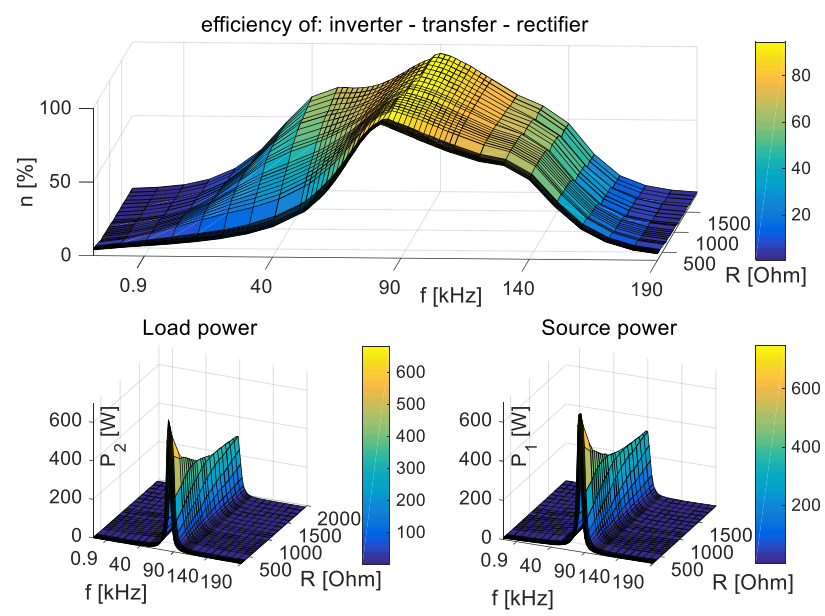

Fig. 10. Measured load power and efficiency of the S-P configuration.

The most significant benefit of the S-S configuration is the highest power ability in comparison with other tested configurations and its lower sensitivity on frequency and the load.

\section{CONCLUSION}

This research analyzed basic operational properties of the WPT system in different resonant tank configurations in order to determine the most useful resonant tank configuration for use in the E-vehicles wireless charging systems.

The compensation configuration is a key design issue having strong impact on the system power and efficiency ability. To be in mutual accordance with the SAE standards, it is necessary to reach efficiency higher than $90 \%$, and power transferred to the load higher than $3.3 \mathrm{~kW}$ (class WPT1).

Based on the study we can present a table (Tab. I) of key operating features for the discussed compensation topologies. The table covers only the system behavior at chosen frequency and distance range while considering constant supply voltage. 
TABLE I.

WPT SYSTEM CONFIGURATION PROPERTIES

\begin{tabular}{|c|c|c|c|c|}
\hline & S-S & S-P & P-S & P-P \\
\hline $\begin{array}{c}\text { Influence of } \\
C_{1} \text { on k }\end{array}$ & none & low & high & high \\
\hline $\begin{array}{c}\text { Influence of } \\
C_{1} \text { on } R_{z}\end{array}$ & none & low & high & high \\
\hline $\boldsymbol{R}_{z}$ for high $\eta$ & lower & higher & lower & higher \\
\hline Maximal $P_{2}$ & high & lower & low & low \\
\hline $\begin{array}{c}\boldsymbol{P}_{\max } \text { and } \\
\eta \text { overlapping }\end{array}$ & no & no & partial & partial \\
\hline $\begin{array}{c}\text { Type of AC } \\
\text { source }\end{array}$ & current & voltage & voltage & current \\
\hline
\end{tabular}

The simulation results and experimental measurement both confirmed the significant influence of the mutual position of the coupling elements and load resistance on the necessary value of the primary compensation capacitor in the P-S and P-P configurations. The S-P configuration has shown the same influence weakness. Only the S-S configuration is fully immune to any changes of the coupling coefficient or the load.

In order to meet the SAE standards, the S-S configuration is strongly recommended for the E-vehicles charging, since it reaches efficiency over $95 \%$ and load power over $5 \mathrm{~kW}$.

Moreover, in a practical application we usually charge the battery pack storage, and hence the current-type output of the resonant tank is required. That operation suits mainly to the S-S or P-P configurations.

\section{ACKNOWLEDGMENT}

This research has been supported by the Ministry of Education, Youth and Sports of the Czech Republic under the RICE - New Technologies and Concepts for Smart Industrial Systems, project No.LO1607, by funding program of the University of West Bohemia number SGS2018-009 and by the centre of competence of rail vehicles TE01020038.

\section{REFERENCES}

[1] E. Atabani, Irfan Anjum Badruddin, S. Mekhilef, and A.S Silitonga, "A review on global fuel economy standards, labels and technologies in the transportation sector," Renewable and Sustainable Energy Reviews, Volume 15, Issue 9, December 2011, Pages 4586-4610, ISSN 1364-0321, https://doi.org/10.1016/j.rser.2011.07.092

[2] W. Su, H. Eichi, W. Zeng, and M. Y. Chow, "A Survey on the Electrification of Transportation in a Smart Grid Environment," IEEE Transactions on Industrial Informatics, vol. 8, no. 1, pp. 110, Feb. 2012. https://doi.org/10.1109/TII.2011.2172454

[3] P. Ning, J. M. Miller, O. C. Onar, C. P. White, and L. D. Marlino, "A compact wireless charging system development," 2013 TwentyEighth Annual IEEE Applied Power Electronics Conference and Exposition (APEC), Long Beach, CA, USA, 2013, pp. 3045-3050. https://doi.org/10.1109/APEC.2013.6520733
[4] G. A. Covic and J. T. Boys, "Modern Trends in Inductive Power Transfer for Transportation Applications," IEEE Journal of Emerging and Selected Topics in Power Electronics, vol. 1, no. 1, pp. 28-41, March 2013. https://doi.org/10.1109/JESTPE.2013.2264473

[5] M. Song, P. V. Kapitanova, and P. A. Belov, "Resonators for wireless power transfer systems," 2017 IEEE Radio and Antenna Days of the Indian Ocean (RADIO), Cape Town, 2017, pp. 1-2. https://doi.org/10.23919/RADIO.2017.8242234

[6] J. G. Kim, G. Wei, M. H. Kim, J. Y. Jong, and C. Zhu, "A Comprehensive Study on Composite Resonant Circuit-Based Wireless Power Transfer Systems," IEEE Transactions on Industrial Electronics, vol. 65, no. 6, pp. 4670-4680, June 2018. https://doi.org/10.1109/TIE.2017.2772207

[7] Juraj Koscelnik, Roman Mazgut, Slavomir Kascak, and Michal Prazenica, "Review of Selected Multi-Element Resonant Topologies," Transactions on Electrical Engineering, Vol. 4 (2015), No. 4, Prague, 2015, ISSN 1805-3386.

[8] P. Spanik, M. Frivaldsky, P. Drgona, and V. Jaros, "Analysis of proper configuration of wireless power transfer system for electric vehicle charging," in 2016 ELEKTRO, Strbske Pleso, 2016, pp. 231-237. https://doi.org/10.1109/ELEKTRO.2016.7512071

[9] P. Spanik, M. Frivaldsky, M. Piri, V. Jaros, and A. Kondelova, "Peak efficiency and peak power point of wireless power transfer system for electromobility applications,", in 2016 ELEKTRO, Strbske Pleso, 2016, pp. 226-230.

https://doi.org/10.1109/ELEKTRO.2016.7512070

[10]S. Y. Chu and A. T. Avestruz, "Transfer-power measurement: A non-contact method for fair and accurate metering of wireless power transfer in electric vehicles," in 2017 IEEE 18th Workshop on Control and Modeling for Power Electronics (COMPEL), Stanford, CA, 2017, pp. 1-8. https://doi.org/10.1109/COMPEL.2017.8013344

[11]A. Kadavelugu, H. Suryanarayana, L. Liu, Z. Pan, C. Belcastro, and E. K. Paatero, "A simple and accurate efficiency measurement method for power converters," in 2017 IEEE Applied Power Electronics Conference and Exposition (APEC), Tampa, FL, 2017, pp. 3265-3270. https://doi.org/10.1109/APEC.2017.7931165

[12]K. Hata, T. Imura, and Y. Hori, "Simplified measuring method of $\mathrm{kQ}$ product for wireless power transfer via magnetic resonance coupling based on input impedance measurement," in IECON 2017 - 43rd Annual Conference of the IEEE Industrial Electronics Society, Beijing, 2017, pp. 6974-6979. https://doi.org/10.1109/IECON.2017.8217219

[13] SAE International, Standards, sae [online], USA: SAE, 2016 [cit. 2017-01-19], avalible on http://standards.sae.org/wip/j2954/

[14] Iveta Tomčíková, "Analysis of Dynamic Circuits in MATLAB," Transactions on Electrical Engineering, Vol. 4 (2015), No. 3, Prague, 2015, ISSN 1805-3386

[15]T. Imura, "Simple equivalent circuit model with foreign object on wireless power transfer via magnetic resonant coupling," in 2017 IEEE Conference on Antenna Measurements \& Applications (CAMA), Tsukuba, 2017, pp. 367-370. https://doi.org/10.1109/CAMA.2017.8273454

[16]P. Spanik, M. Frivaldsky, M. Piri, and V. Kindl, "Wireless power transfer system with reduced voltage stress on compensation capacitors," in IECON 2016 - 42nd Annual Conference of the IEEE Industrial Electronics Society, Florence, 2016, pp. 1190-1195. https://doi.org/10.1109/IECON.2016.7793103 